\title{
The survey of impact of entrepreneurial courses on intention and psychological characteristics of physical education students (a case study of Iranian universities)
}

\author{
Fahimeh REZAEI, Ali ZAREI, Faride Ashraf GANJOUEI
}

Department of Sport Management, Islamic Azad University, Tehran Central Branch, Iran.

Address Correspondence to F. Rezaei, e-mail: fahimehrezaeitehran@gmail.com

\begin{abstract}
Recently, according to increasing growth of young population and limitations of employment opportunities, empowering youth and their guidance toward entrepreneurship has been the most important country authorities' programs. In spite of detection of the importance of sport in the knowledge economy and entrepreneurship and efforts by universities in the country and the Ministry of Sport and Youth in order to teach entrepreneurship, effect of entrepreneurship education in physical education students and higher education institutions has not been studied. Therefore, the primary purpose of this paper is to study and evaluate effect of entrepreneurship education in schools of physical education in the Iran. Thus, one of the most important actions, in order make entrepreneurial behavior in them, is to form entrepreneurial intend and attitude in them. The research method is descriptive and applied one. Statistical population of this study includes all physical education colleges affiliated to the Ministry of Science, Research and Technology. Target population includes all students existed in schools as well as individuals who were registered. A validity questionnaire having the stability $\alpha=0 / 91$ was used in order to collect data. Data analysis was performed in two levels by using spss18 software. Results show that entrepreneurship intention of participants in entrepreneurship classes is different than students who do not participate in entrepreneurship classes. In fact, students participated in entrepreneurship classes are more inclined to entrepreneurship. Among contents and popular headlines to train entrepreneurship, the issues such as marketing, principles of launching business, innovation, entrepreneurial characteristics and definitions and concepts of entrepreneurship were presented for students in classes. This study presented basis for accepting additional research on sport-entrepreneurship education. Also, it provides valuable perspectives for universities and other sectors in order to determine the basic characteristics of effective teaching methods in the field of Sport Entrepreneurship that is along with national entrepreneurship development action plan.
\end{abstract}

Keywords: Entrepreneurial intention, physical education students, psychological characteristics, sport entrepreneurship.

\section{INTRODUCTION}

Work and entrepreneurship is the most important Social and problem and also it a humansocial process that has a strong link with socioeconomic changes and it is considered as one of the cheapest tools having the best results and the highest performance. Therefore, in communities, it is essential that entrepreneurial revolution to be occurred (1). Entrepreneurial revolution has been influenced around the world and this influence has been observed in the business world (10). Studies show that entrepreneurship is educable and has the ability to reinforce (6). Therefore, teaching entrepreneurship can be one of the most effective ways to facilitate transferring more responsibility population to the labor market (3). Entrepreneurship Development is investigated from various perspectives that education is one important aspect that is along with it (9). According to the European Commission (2006), politicians believe that levels of entrepreneurship increases through teaching especially teaching entrepreneurship (4).

David McClellands was the first psychologists who assume that entrepreneurs need for high achievement and he planned several training courses in order to reinforce this need in individuals so that he received positive results from Training these courses with Indian businessmen (2). Different countries use entrepreneurship education in order to promote entrepreneurship. In Finland, entrepreneurship education is widely used in the secondary school curriculum. Also, Great Britain and Spain perform entrepreneurship education activities. Other countries such as Germany, Australia and Switzerland have begun to significant efforts for teaching entrepreneurship. Also, in Iran, 
economic, political and cultural conditions in recent years has been caused that the subject of entrepreneurship be considered in development program especially in the field of management and entrepreneurship training and in this regard, credits has been forecasted(8).

In academic sector, knowledge storage in not satisfied, but ensuring application of knowledge so that society can use interests of investors in researches is one of the main objectives of academic research. Therefore, for the senior politicians and socio-political decision-makers in developed countries, it has been revealed that new function of universities plays important role in the economic and technological development of society (3).

Sport is a growing social and economic phenomenon that deals with different dimensions and functions in society. In sport sciences, entrepreneurship can occur in fields such as sports management, sports coaching, sports and physical education, health and etc. (13). Sport as one of the effective factors on the areas of social, economic and even international has been considered in many countries of the world. Hence, it can organize and promote policies such as entrepreneurship and job creation through it. This is possible if in addition to promotion and introduce sport entrepreneurship in society, especially among graduates of physical education, problems facing the education and development of the sport entrepreneurship be solved in order to provide a powerful tool to achieve sustainable economic and social development.

The purpose of this study is to investigate the impact of entrepreneurial courses on intention and psychological characteristics of entrepreneurship of physical education students. The questions raised are: 1) What are types of the teaching methods? (Eg case studies, business plans, use of guest instructor, etc). 2) How is level of the effect of different methods of teaching for physical education students? 3) How was familiarity with entrepreneurship courses?

\section{MATERIAL \& METHOD}

Research method was Descriptive survey and practical. The study population includes all physical education colleges affiliated to the Ministry of Science, Research and Technology. Sampling was performed among above colleges. Within colleges, all students registered in entrepreneurship classes. Also the subjects that did not register were target population $(\mathrm{N}=186)$.
Different methods were used in order to gather the required information. In the documentary studies, library documents were used to access the data in theoretical part of this study. In the other part of this research that has been conducted as a field research, scholar questionnaire was used. Based on answers, questions were used in 5 values Likert scale. Totally, the questionnaire consists of four main sections. First section of the questionnaire deals with the demographic characteristics of sports entrepreneurs, and second section is related to the course content. The third section examines teaching methods and finally, the fourth section also deals with features assessment and trends about entrepreneurship. Validity of the questionnaire was assessed by professors and experts in physical education and entrepreneurship and its reliability was measured through Cronbach's alpha test at a significance level of $\mathrm{P} \leq 0.05(\alpha=0.91)$.

After completing the questionnaire by the subjects and transfer data to a computer, data processing and statistical analysis were performed by using SPSS software. In order to perform descriptive analysis, frequency distribution tables were drawn. Inferential analysis was conducted according to the objectives of research and, by considering the scale variables of Cronbach's alpha test (for reliability), Kolmogorov-Smirnov (for normal distribution), $t$ (for comparing the average of two groups) and Leven.

\section{RESULTS}

\section{The demographics of students}

In order to Understanding the demographic characteristics of the selected sample have been questions in the questionnaire: The gender, age, marital status, Students' academic year, Level of education, which are discussed each separately.

\section{A) Gender}

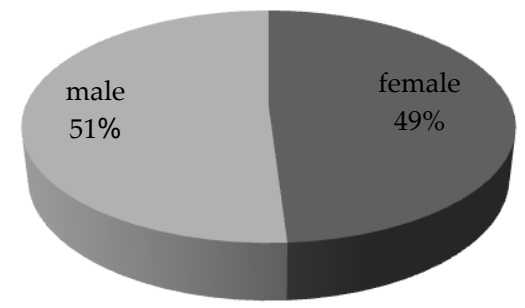

Figure 1. Characteristics of the sample population of students by gender. 
As can be seen above in the diagram, the numbers of male and female students were close together, but most of the students are men. This means that women are 49 percent and males are 51 percent.

\section{B) Age}

As can be seen in the charts above, Age range of Students are between 20 and 43 years that Most of the students are in the range of 25-21 years and lowest under 20 years of age.

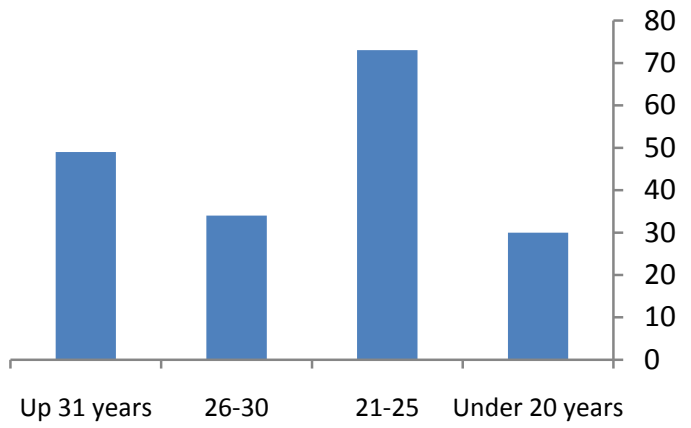

Figure 2. Age distribution of students.

Table 1. Frequency and age range of students

\begin{tabular}{lcccc}
\hline Age range & Frequency & Percent & $\begin{array}{c}\text { Valid } \\
\text { percent }\end{array}$ & $\begin{array}{c}\text { Cumulative } \\
\text { percent }\end{array}$ \\
\hline Under 20 & 30 & 16.1 & 16.1 & 16.1 \\
$21-25$ & 73 & 39.2 & 39.2 & 55.4 \\
26-30 & 34 & 18.3 & 18.3 & 73.7 \\
Above 31 & 49 & 26.3 & 26.3 & 100 \\
Total & 186 & 100 & 100 & - \\
\hline
\end{tabular}

\section{C) Marital status}

Most students (53.2 percent) are married and 47.8 percent are single (Figure 3 ).

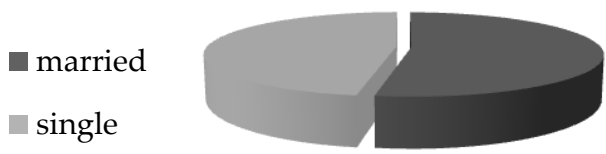

Figure 3.Marital status students.

\section{D) Students' academic year}

According to Table 2, more students are studying at the second year and then students at the third-year (29/6 percent), the first year (17.2 percent), and fourth (17.6 percent) come respectively.
Table 2. Students' academic year.

\begin{tabular}{lcccc}
\hline $\begin{array}{l}\text { Academic } \\
\text { year }\end{array}$ & $\begin{array}{c}\text { Cumulative } \\
\text { percent }\end{array}$ & $\begin{array}{c}\text { Valid } \\
\text { percent }\end{array}$ & Percent & Frequency \\
\hline $1^{\text {st }}$ year & 32 & 17.2 & 17.2 & 17.2 \\
$2^{\text {nd }}$ year & 66 & 35.5 & 35.5 & 52.7 \\
$3^{\text {rd }}$ year & 55 & 29.6 & 29.6 & 82.3 \\
$4^{\text {th }}$ year & 29 & 17.6 & 17.6 & 97.8 \\
After $^{\text {th }}$ year & 4 & 2.2 & 2.2 & 100 \\
Total & 186 & 100 & 100 & - \\
\hline
\end{tabular}

\section{E) How familiarity with entrepreneurship courses}

As can be seen in the above table, $8 / 34$ percent have participated in entrepreneurship classes as a result of the proposed professors and others Participated in entrepreneurship classes for Suggestion of Friends and classmates (8/22 percent), Itself of experience and interest (30.4 percent), promotional programs entrepreneurship center $(1.1 \%)$ and optional lessons (4.5 percent) and 4.5 percent in entrepreneurship classes participated unspecified reasons. 4.5 percent for reasons unclear.

\section{F) Future career plans of students}

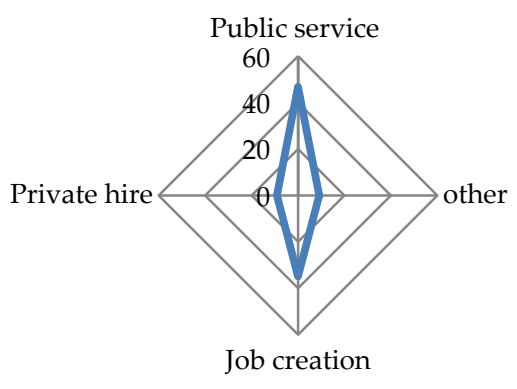

Figure 5. The future career plans students.

Students were asked what their plans for the future of their profession? The results of this question are shown in the following diagram.

As shown in Figure 5 can be seen, most of students are seeking employment in the public sector(46/8 percent); also after which are placed Business startup (34.9 percent), Private sector employment $(9.1 \%)$ and Etc. (9/1percent). It is noteworthy in this regard that accordance to Civil Service Law At the same time employment in the public sector is prohibited and by giving the private sector to the government will change the patterns and programs. A number of students also said that First, they tend to be employed in the private sector and after gaining experience they start up their own business. However, the percentage of those seeking to set up their business is striking. Because this amount (34.9 percent) has been promising number 
proportionally, it is hoped that this program become into practice in the future.

\section{G) Effective teaching methods}

The students were asked which of the teaching methods used in entrepreneurship classes was more effective that the results are as follows: As shown in Figure 7, from of 15 kinds of teaching methods listed for Entrepreneurship (Case study, Codification of Business plan, Speaking of Entrepreneurs, computer simulation, Speaker (teacher) Guest, Counseling programs, Research Projects, Feasibility studies, internship, Visit Business, Class exercises, Video streaming entrepreneurs, Entrepreneurship sites, Business plan competition, and Application BPP) 9 type of teaching was used for students method (Case study, Speaking of Entrepreneurs, speaker (teacher) Guest, Counseling programs, Research Projects, internship, Class exercises, Video streaming entrepreneurs, Entrepreneurship sites ) and the six variant have been neglected (Codification of Business plan, computer simulation, Feasibility studies, Visit Business, Application BPP, Business plan competition).

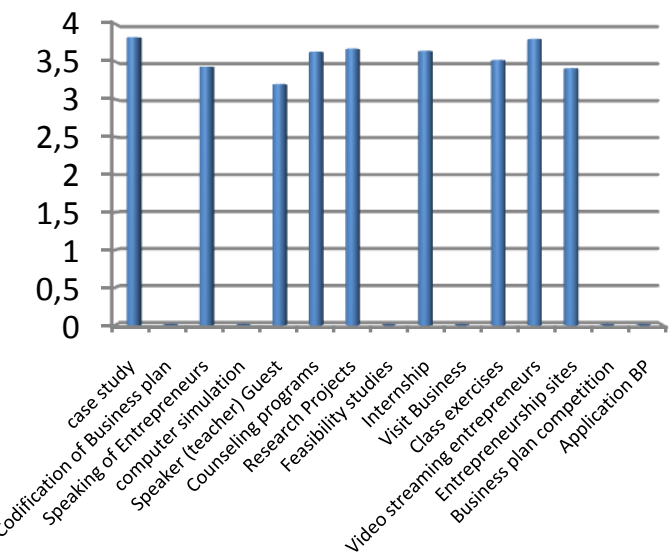

Figure 6. A variety of teaching methods and the impact on students.

As you can see in Figure 6; According to opinion of the participating students in entrepreneurship classes, the case study method of teaching, research projects $(12 \%)$ were more effective than other teaching methods used to teach entrepreneurship.

\section{Course content}

The students were asked "Which of the issues raised in entrepreneurship classes was effective and practical for them. The result of this question is shown in Table 5.

Table 5. Course content and its impact on students

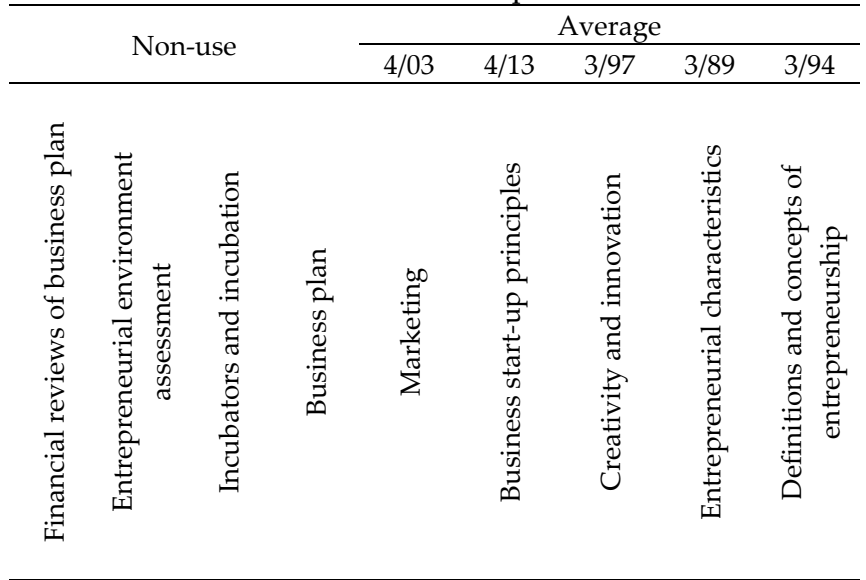

As shown in Table 5, among content and common topics listed for teaching entrepreneurship, 5 cases of them (i.e. marketing, business start-up principles, creativity and innovation, entrepreneurial characteristics and definitions and concepts of entrepreneurship) were presented in entrepreneurship classes for students. Other topics such as incubators and incubation, entrepreneurial environment assessment, business plan and financial reviews of business plans have been neglected. Moreover the topics covered in entrepreneurship classes did not affect very high on students.

\section{Entrepreneurship intention and characteristics}

As shown in Table 6, Average of samples statistics for both groups on entrepreneurial intention (2.46 and 1.72) shows a clear difference between. Table 7 illustrates the significance of this difference. But, there is no difference between the two groups in section on psychological characteristics of entrepreneurship.

Table 6. Entrepreneurship intention and characteristics

\begin{tabular}{|c|c|c|c|c|}
\hline Group & & $\mathrm{n}$ & Mean & $\mathrm{SD}$ \\
\hline \multirow{2}{*}{$\begin{array}{l}\text { Entrepreneurship } \\
\text { intention }\end{array}$} & Participant & 92 & 2.46 & 0.25 \\
\hline & Not Participant & 94 & 1.72 & 0.37 \\
\hline Internal locus & Participant & 92 & 3.28 & 0.46 \\
\hline 范 $\cong$ of control & Not Participant & 94 & 3.18 & 0.57 \\
\hline 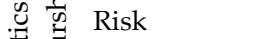 & Participant & 92 & 3.09 & 0.52 \\
\hline$\stackrel{\vec{D}}{\vec{D}}$ & Not Participant & 94 & 3.18 & 0.56 \\
\hline 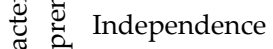 & Participant & 92 & 3.37 & 0.47 \\
\hline 䒕 & Not Participant & 94 & 3.33 & 0.38 \\
\hline 厄゙ 己્ટ Achievement & Participant & 92 & 3.19 & 0.47 \\
\hline & Not Participant & 94 & 3.18 & 0.45 \\
\hline
\end{tabular}


Table 7. Independent sample test for Entrepreneurship intention.

\begin{tabular}{lccccc}
\hline & \multicolumn{2}{c}{ Levene's test } & \multirow{2}{*}{$\mathrm{t}$} & $\mathrm{df}$ & $\mathrm{p}$ \\
\cline { 2 - 4 } & $\mathrm{F}$ & $\mathrm{p}$ & & & \\
\hline $\begin{array}{l}\text { Entrepreneurship } \\
\text { intention }\end{array}$ & 9.749 & 0.002 & 15.905 & 184 & 0.000 \\
\hline
\end{tabular}

We present $t$ value and its critical value and the confidence interval for the difference. Also, we answer this question "Is the difference between the two groups statistically significant or not?" All this values are presented in two cases (i.e. by assuming equality of variances and without consideration of equality of variances).

Since, Levene test for homogeneity of variances assumption is not significant in t-test $(p<0.05)$, variances cannot be assumed to be uniform as well as the presented value cannot be used in the line where variances assumed to be equal. Therefore, we can say that value calculated by using a variance combination (by assuming inequality of variances) is appropriate. Bothare significant by the critical value of less than 0.01. It means that entrepreneurship trend of participants in entrepreneurship classes is different from students who did not participate in entrepreneurship classes. Generally, students participating in entrepreneurship classes are more willing to entrepreneurship.

\section{DISCUSSION}

The purpose of the present study is to evaluate impact of teaching entrepreneurship in physical education colleges. For this, students in physical education colleges across the country who were passed entrepreneurship courses and who were not passed entrepreneurship courses were used .Based on the findings, the group that had passed entrepreneurship courses had more trends than to others. Their purpose was to identify factors that show differences between students' intention for starting a business. These findings are consistent with results of Dopaco et al. (4). They studied entrepreneurial intentions and behavior of high school students between 15-14 years old. Also, they used Eisen planned behavior model. Results of studies show that Eisen planned behavior model is an appropriate tool for the development of entrepreneurial intention through processes of teaching for early childhood and their learning backgrounds. Also, Education and training should be more focused on changing the attitudes of human instead of the knowledge. In addition, it is desirable that entrepreneurship training programs be applied in order to develop capabilities related to entrepreneurial and social skills and cultural awareness. Linan et al. (11) studied the role of training in different levels of entrepreneurial intention. In addition to evaluate Eisen and shipper model, they used the standard questionnaire of entrepreneurial intention. They concluded that Training has significant impact on people's attitudes and entrepreneurship intention and Fayolle et al. (5) studied impact of entrepreneurship training programs. They concluded that entrepreneurship training programs influence on entrepreneurial intentions. Also, Peterman and Kenedy investigated impact of participating in entrepreneurship training courses in Australia and concluded that more experienced people and people who have had positive experiences and incentives in the field of entrepreneurship were more interested in participating in entrepreneurship training courses. Also, the feasibility and desirability of establishing business after the passing the course has increased significantly. But the results of Stherbik et al. (2008) revealed that there is no significant relationship between training and entrepreneurial intention of people.

Practical proposals:

1) Paying attention to the sport entrepreneurial spirit in the educational system of country and physical education colleges, and as a result, increase the possibility of employing in the private sector and self-employment activities.

2) The corresponding formal and non-formal training for sports entrepreneurship to the needs of the labor market.

3) Introducing successful sport entrepreneurs to physical education students in the Faculty of Physical Education.

4) The inclusion of educational programs in the undergraduate and graduate educational course content on sport entrepreneurship.

5) The possibility of visiting students from successful sport entrepreneurial projects and adapting academic curriculum with labor market needs to revise the program and lessons content of physical education field.

6) Requiring physical education graduate students to present a business plan related to his/her thesis.

7) Using a variety of different methods of teaching in teaching sport entrepreneurship.

8) The use of technologies and new training methods in sport entrepreneurship. 
9) Training how to write a sport business plan to enthusiasts of sport entrepreneurship.

10) Encouraging and supporting students and staff for sport creative initiatives of faculty of physical education.

11) Training feasibility studies of implementing business plan to students interested in sport entrepreneurship

12) Establishing networks of graduations for sport graduates for experienced people to use role models, creating connections with venture capital and business angels, etc.

13) Conducting training courses to prepare students in physical education to enter the labor market

14) Providing supports required for in order to exchange entrepreneurship professors among different universities.

Research proposals:

1) The survey of challenges and strategies for the development of entrepreneurship among graduates of physical education and sports

2) Evaluate the effectiveness of entrepreneurship curricula in the Faculty of Physical Education

3) Evaluate the effectiveness of entrepreneurship education from the perspective of physical education students

4) The Survey of role of attitude toward the behavior, subjective norms, and perceived behavioral control physical education students' entrepreneurial intentions

5) A study on determining the content of sports entrepreneurship training courses

6) A study on how to implement various entrepreneurship courses in the fields of physical education and sports effective way.

7) A study of ways to increase student interest in entrepreneurship physical education and sports

8) A study on obstacles of students' relation and faculty of physical education to industry and labor market and provide solutions to improve it.

\section{REFERENCES}

1. Aliakbar A. Instructor training course in entrepreneurship, entrepreneurship training workshop: concepts, theories and necessity, Mazandaran University, 1387.

2. Ahmdpour DM. Entrepreneurship: (theories, definitions, templates), Tehran, pardis publications, 1387.

3. David U, Marines A, Nuriatoledano. Doctoral education in entrepreneurship: a European case study. Journal of Small Business and Enterprise Development, 2008; (15)2.

4. DoPaco A, Ferreira J, Raposo M, Rodrigues, R Dinis, A. Entrepreneurial intention among secondary students: findings from Portugal. International Journal of Entrepreneurship and Small Business, 2011; (13)1: 92-106.

5. Fayolle A, Basso O, Bouchard V. Three levels of culture and firms entrepreneurial orientation: A research agenda. Entrepreneurship \& Regional Development, 2010; (22) 7/8: 707-730.

6. Feyzbakhsh B, Seyed A, Dehghanpour FA. Decision-making process starts Entrepreneurship (CASE STUDY Iranian entrepreneurs), Knowledge Management, 1381; 58: 84-67.

7. Haji MR, Rapporteur DA. Entrepreneurship training and development in the higher education system Applied Science Agriculture, Agricultural Education Management Journal, $1388 ; 9,84-81$.

8. Hosseini M. The impact of entrepreneurship education on students' perceptions of entrepreneurship, Master Thesis, School of Management, Tehran University, 1387.

9. Khosravi S, Chyzry M. Examines the impact of entrepreneurship education for rural youth entrepreneurial intention of Kermanshah. The Second Conference of Student Entrepreneurs, 1391.

10. Kuratko DF. The Emergence of Entrepreneurship Education: Development Trends, and Challenges. Entrepreneurship Theory and Practice, 2005; (5)29: 577-598.

11. Liñán F, Rodríguez Cohard J, Rueda CJ. Factors affecting entrepreneurial intention levels: a role for education. International Entrepreneurship and Management Journal, 2010; (7)2: 195-218.

12. Peterman N, Kennedy J. Enterprise Education: Influencing students, Perceptions of Entrepreneurship. Entrepreneurship Theory and Practice, 28(2): 129-121.

13. Peterman N, Kennedy J. Enterprise Education: Influencing students, Perceptions of Entrepreneurship. Entrepreneurship Theory and Practice, 28(2): 129-121.

14. Peixoto N, Ana Maria. Entrepreneurship education in sport sciences: implications for curriculum development. Faculdade de Motricidade Human, Universidade de Lisboa, 2013, pp. 57.

15. Saeedi MM, Mohtadi MM. The impact of education on the development of entrepreneurial behaviors, development of entrepreneurship, the Second Number, 1387: S73-57.

16. Zali SM, Reza M, Razavi, Yadollahi P, Jahangir, Nayyj A. Assess the status of entrepreneurship in Iran, first edition, published by the Institute of Labor and Social Security, 1389 . 